\title{
Comparison of Constitutive Models for Predicting the Formability of SS 304 by Tubular Hydroforming Process
}

\author{
Pathapalli Venkateshwar Reddy, Vardhaman College of Engineering, India \\ (iD) https://orcid.org/0000-0002-1012-7510 \\ B. Veerabhadra Reddy, G. Pulla Reddy Engineering College, India \\ Perumalla Janaki Ramulu, Adama Science and Technology University, Ethiopia* \\ U. Pranavi, Vardhaman College of Engineering, India
}

\begin{abstract}
Finite element (FE) simulation of sheet/tube forming precision depends mainly on the accuracy of the constitutive modeling. The paper aims to compare the constitutive models to fit the stressstrain curves. The accurate deformation behavior of the SS 304 tubes depends on the constitutive modeling of hardening behavior. Deformation data of the tensile specimens cut from tubular sample were collected by conducting uniaxial tensile tests (UTT) at three different rolling directions. Five constitutive relationships were then recognized by fitting the true stress and strain data with the constitutive models of Hollomon, Power, Krupowsky, Voce and Ghosh, and the fitting accuracy were analyzed and compared. Effects of hardening models on forming limit curves (FLC), pressure loading, and bulge height of the hydroformed tube were then studied. The obtained FLC from the simulations were compared with experimental FLC to predict the accuracy of the hardening models.
\end{abstract}

\section{KEYWORDS}

Bulge Height, Constitutive Modeling, FLC, SS 304, Tube Hydroforming

\section{INTRODUCTION}

Tube hydroforming (THF) is a high-tech manufacturing method that creates precise shapes with precise dimensions. Though THF techniques are utilised in various industries such as automotive and aerospace, the development of the process requires expensive tools because the process is based on experimentation. THF is widely employed in various industries to accomplish weight reduction, fewer parts, and lower costs (Ge et al., 2017) due to significant advancements in PC controls and pressure drive frameworks. A brief summary on THF can be observed in literature (Alaswad et al., 2012). The higher formability of materials means to create successful forming behavior. There are many methods in the form of analytical and experimental models developed to generate FLC for different 
sheet metals. FLC was first introduced by Keeler (Keeler, 1961), later; many researchers have worked on the formability of sheet metal with the help of numerical and experimental methods (Hashemi et al., 2014; Safikhani et al., 2009; Zhang et al., 2018). But, the inference of FLCs by THF is a novel area in view of the difficulties connected with the process. The noteworthy process of disappointment in this action is predictable to wrinkling and bursting. The reasons for these types of failures were already explored in the literature works (Alaswad et al., 2012; Ge et al., 2017; Wang \& Peng, 2016).

Based on the above statements, it is clearly understood that there are many pitfalls in the THF that are to be explored in order to improve the utilization of the process. To initiate these issues, many works have been carried out to predict strain records which aren't continuous by the controlled experimental facts as explained by Asnafi and Skogsgardh (2000) in their work. Zhang et al. (2011) surveyed various necking criterions which are usually applicable to botht sheet and tube forming process. To investigate the necking criterions, $\mathrm{Al} 5086$ was considered to study the formability based on numerical simulation. The obtained results are in good connection with the experimental results in terms of failure and loading predictions. Thanakijkasem et al. (2015) developed and compared various FE models with the experimental values of SS 304 for THF process. FLC of SS 304 was taken into consideration to explore the formability of the tube during THF. The developed models were compared and analyzed and the prediction capability were explained in the study. Naghibi et al. (2016) developed a novel technique for the prediction of FLC for SS 304 during THF process. The authors considered the influence of process parameters on the FLC prediction and strain generations. The work finally concluded that developed method has a significant influence of process parameters in the accurate prediction of FLC during THF process. Wang et al. (2015) investigated on the constitutive modeling of the tubular material based on two different theories; total strain energy theory and incremental theory. The work presented the comparison of data from both the theories with the existing simulation data. The work concluded that the data obtained from total strain energy theory is in good agreement with the existing simulation data.

Yuenyong et al. (2018) analyzed the forming behavior of SS 304 using hydroforming technology. Finite element simulation was also carried out in connection with damage modeling for accurate prediction of the bulged tube. Different boundary conditions were considered for obtaining the left hand and right hand side of the FLC. The obtained results of the tube bulge test were compared with sheet bulge test for prediction of forming behavior. Ghazani \& Eghbali (2018) worked on the ductile damage criterion and damage values were calculated by considering two parameters namely strain rate and deformation temperature. From the results, it was concluded that the damage value and deformation temperature were directly proportional whereas strain rate was inversely proportional. Hashemi et al. (2009) developed a theoretical forming limit stress diagram by considering M-K model. The results confirmed that the present developed was able to predict the necking in tube hydroforming process for various boundary conditions. Zribi et al. (2013) proposed a new inverse identification method for the prediction of flow stress behavior of tubular material even by the consideration of anisotropic effects. The identified flow stress predicted the accurate deformation behavior of the tubular specimen during THF process.

Based on literature works, it is quite familiar to understand that many efforts were placed to launch the forming limit curve (FLC) by conducting experiments and few by numerical simulations. So, the aim of the present paper is to fit different hardening laws of SS304 tubes using uniaxial tensile test (UTT) and the obtained deformation data were used for further processing. Fitting the true stress and strain data to five known constitutive models of Hollomon, Power, Kruposky, Voce, and Ghosh yielded five constitutive expressions. The constitutive relationships that were discovered were evaluated and contrasted. The paper is unique in that it investigates FLC prediction for THF processes using several hardening models. According to the highlighted gap, the current study investigated the tube bulging of SS 304 using various hardening models and compared the experimental results. The simulations were conducted on various hardening models up to the bursting of tubes. The FLCs obtained by numerical simulations were compared with experimental FLC in order to predict the accuracy of 
the hardening models. The main novelty of the current work is to compare the numerical solution in terms of loading behavior, bulge height and FLD to the experimental results. The consequence of the hardening models on the formability of SS 304 tubes during THF process was also explored.

\section{MATERIALS AND METHOD}

This section explains the materials and methods used in the present study for the investigation of tube formability in THF process.

\subsection{Tube Material}

The tube material employed in this investigation was SS 304, and Table 1 shows the chemical composition of SS 304. Using a gas cutting machine, the tensile test samples were cut to ASTM E8 standard dimensions from SS 304 tubes of $1 \mathrm{~mm}$ thickness.

\subsection{Tensile Tests}

In this work, $60 \mathrm{~mm}$ diameter SS 304 tubes with a $1 \mathrm{~mm}$ wall thickness were used. On an INSTRON machine with a maximum load capacity of $50 \mathrm{kN}$ and a crosshead speed range of $0.05-500 \mathrm{~mm} / \mathrm{min}$, a Uniaxial Tensile Test (UTT) was performed. At three different rolling directions, tensile and R-bar (Lankford anisotropy values) tests were performed. Based on the literature (Reddy et al., 2019), the specimen dimensions for obtaining lankford coefficients and tensile properties were assessed. The specimens were taken out from the tubular sample at three different orientations for obtaining the lankford coefficients. The obtained mechanical properties from the UTT and R-bar tests were tabulated in Table 2 .

\subsection{THF Experiments on SS 304 Tubes}

All experiments were carried out at the authors' institute in Kurnool, Andhra Pradesh, INDIA. The experimental test equipment for tube bulging was created at the institute and can be shown in fig. 1 . Tubes with a diameter of $200 \mathrm{~mm}$ were utilised to bulge, and the same length of tube was modelled for simulations as well. The dies were made with a $10 \mathrm{~mm}$ corner radius because the author's earlier work showed that such corner radii produced the greatest results (Reddy et al., 2019). The tube is fixed into the die and the both ends are sealed mechanically. After sealing the tube ends, internal pressure inside the tube is increased steadily with the help of hydraulic pump. The bulging of the tube is noted for each step increment of the pressure into the tube.

\subsection{Numerical Simulations}

Uni-axial tensile tests were used to obtain the input data needed for simulations. CATIA V5R11 was used to simulate all of the tools required for completing THF process simulation. These tools are

Table 1. Chemical composition of SS 304 material

\begin{tabular}{|l|l|l|l|l|l|l|l|l|l|}
\hline Elements & $\mathrm{Cr}$ & $\mathrm{Ni}$ & $\mathrm{Mn}$ & $\mathrm{C}$ & $\mathrm{Si}$ & $\mathrm{S}$ & $\mathrm{Al}$ & $\mathrm{Cu}$ & $\mathrm{Fe}$ \\
\hline SS 304 (wt. \%) & 17.91 & 8.94 & 1.78 & 0.016 & 0.492 & 0.031 & - & 0.041 & Balanced \\
\hline
\end{tabular}

Table 2. Obtained Mechanical Properties of SS 304 sheets

\begin{tabular}{|l|l|l|l|l|l|l|l|l|}
\hline Material & Thickness $(\mathrm{mm})$ & $\mathrm{R}_{0}$ & $\mathrm{R}_{45}$ & $\mathrm{R}_{90}$ & $\sigma_{0}(\mathrm{MPa})$ & $\sigma_{45}(\mathrm{MPa})$ & $\sigma_{90}(\mathrm{MPa})$ & $\mathrm{E}(\mathrm{GPa})$ \\
\hline SS 304 & 1 & 1.08 & 0.96 & 1.05 & 390 & 375 & 384 & 210 \\
\hline
\end{tabular}


Figure 1. Tube hydroforming experimental Test setup

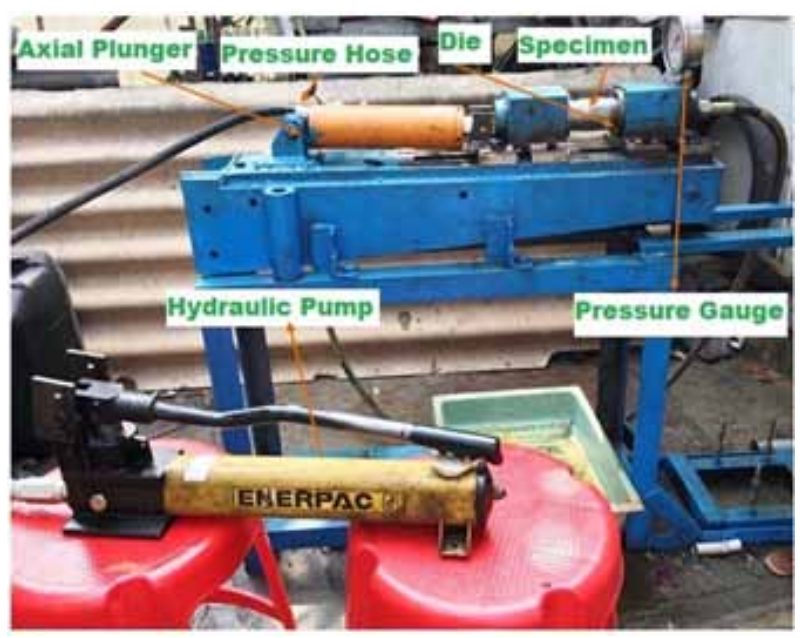

then imported into the PAM-STAMP 2G analysis package. Literature (Reddy et al., 2019; Reddy et al., 2020; Reddy et al., 2018; Wang et al., 2016) provide a full account of the numerical simulation and the genesis of FLC. As per four noded shell elements, tube is meshed with a mesh size of 1 . The simulations were run using five alternative hardening laws and the Hollomon 1990 yield criterion in order to compare the results to those achieved experimentally. A coefficient of friction value of 0.05 was considered based on the previous work of the authors (Reddy et al., 2019).

\subsection{Forming Limit Curves (FLC)}

According to the literature (Omar et al., 2015), FLC is a useful method for determining the strains at which a material deforms without failing (necking, bursting, and wrinkling). The forming limit curve is used to prepare the FLD by joining the necked regions (FLC). The THF procedure was utilised to examine formation limit strains by comparing alternative hardening models used for numerical simulations with experimental data for tube bulge tests. The strain hardening is a measure of the plastic deformation and which is a continuous without sudden change in the loading-paths, moreover the stress behavior of loading-unloading- reloading are not well taken into the account. Internal pressure loading was created to form the tubular specimens into the desired shape in which have circular grids over the tubular specimen. Simulations were performed with different boundary conditions to construct the full FLC. The detailed description of the various boundary conditions which are required to construct the FLC for the tubular specimens is discussed in the literature (Pambhar \& Narasimhan, 2013).

\section{CONSTITUTIVE MODELING}

The plastic deformation of sheet/tubular specimen will undergo the strain-hardening course of action. There are various mathematical models which describes the plastic behavior of sheet/ tube metal. These models were utilized by fitting the experimental tensile test data or some other non-recognized test data also. Strain hardening behaviors are especially divided into two groups. The first group defines the saturated stress at high strain rate, Voce law comes under this condition (Voce, 1948). Hardening behavior of FCC structured metals like aluminum and copper can be modeled by this method because of presence of high saturated stress at high strain 
rate. Moreover, hardening behavior of BCC structured metals can be modeled by using power, ghosh and krupowsky laws which posses unbounded stress at high strain rate. Some research groups investigated the hardening behavior by combining two hardening models also (Papasidero et al., 2015). A systematic review on the importance of hardening models can be found in the literature (Gronostajski, 2000). To determine the influence of the hardening law behavior on the flow stress of SS 304 metal, five hardening models: Hollomon; Power; Krupkowsky; Voce and Ghosh hardening models were used to fit the experimental UTT data. The fitting of hardening models until the failure point can be observed in fig. 2. From the fig. 2, it is observed that except hollomon law all the hardening models produced similar flow curves. While, ghosh and power law attained high accurate flow curve. The differences between all the hardening flow curves were highly significant which usually yields different FLC predictions. Five constitutive hardening laws were used to fit the obtained true stress-strain curve using Matlab and the obtained results are represented in Table 3. The fitting curves are illustrated in fig. 2, whereas the model constants and their predictive capability in terms of $\mathrm{R}^{2}$ were tabulated in Table 3 . In the present study, it was observed that hollomon law under estimated the flow stress whereas power law over estimated the flow stress because of higher deformations. The obtained values of $\mathrm{R}^{2}$ is based on the curve fitting model with the experimental data. RSME is obtained based on the errors in the predictive model. The formulae used for finding out the $\mathrm{R}^{2}$ is shown in equation 1 but here in the study, $\mathrm{R}^{2}$ is obtained directly from the software. With each predictor added to a model, $\mathrm{R}^{2}$ rises. $\mathrm{R}^{2}$ always grows and never lowers, therefore the more terms you add to the model, the better it appears to fit. This can be really deceiving. Similarly, if your model contains too many terms and high-order polynomials, you may have over-fitting of the data. A misleadingly high $\mathrm{R}^{2}$ score might lead to deceiving estimates when data is over-fit:

$$
R^{2}=1-\frac{\sum_{i=1}^{n}\left(Y_{i \text { Pred }}-Y_{\text {iexpt }}\right)^{2}}{\sum_{i=1}^{n}\left(Y_{\text {avg,Pred }}-Y_{i \text { Pred }}\right)^{2}}
$$

Figure 2. Various hardening models fitting with the experimental tensile test data

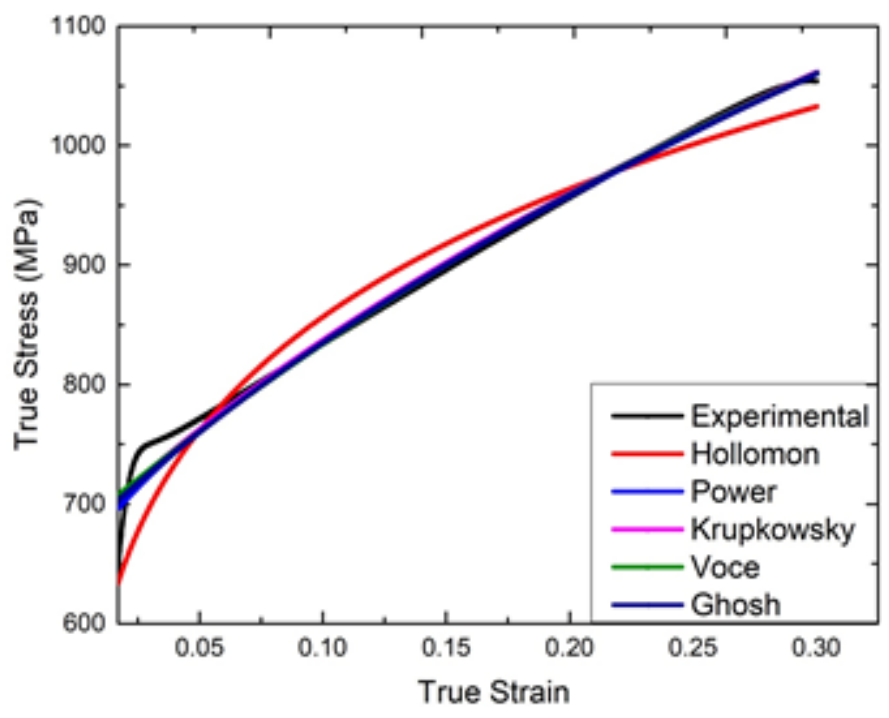


International Journal of Manufacturing, Materials, and Mechanical Engineering

Volume $12 \cdot$ Issue 1

Table 3. Hardening model constants and their predictive capability

\begin{tabular}{|l|l|l|l|}
\hline Constitutive Models & Model Expression & Parameters & \multicolumn{1}{|c|}{ UTT Values (Accuracy and Mean Square Error) } \\
\hline Hollomon Law & $\sigma=\mathrm{k} \varepsilon^{\mathrm{n}}$ & $\mathrm{k}, \mathrm{n}$ & $\begin{array}{l}\mathrm{k}=1267, \mathrm{n}=0.1701 \\
(\mathrm{R}-\mathrm{sqr}=0.9571 \& \mathrm{RMSE}=21.41)\end{array}$ \\
\hline Power Law & $\sigma=\mathrm{a}+\mathrm{b} \varepsilon^{\mathrm{n}}$ & $\mathrm{a}, \mathrm{b}, \mathrm{n}$ & $\begin{array}{l}\mathrm{a}=636.8, \mathrm{~b}=964.9, \mathrm{n}=0.6833 \\
(\mathrm{R}-\mathrm{sqr}=0.9859 \& \mathrm{RMSE}=12.27)\end{array}$ \\
\hline Krupkowsky Law & $\sigma=\mathrm{k}\left(\varepsilon_{0}+\varepsilon_{\mathrm{p}}\right)^{\mathrm{n}}$ & $\varepsilon_{0,} \mathrm{k}, \mathrm{n}$ & $\begin{array}{l}\varepsilon_{0}=0.1253, \mathrm{k}=1461, \mathrm{n}=0.374 \\
(\mathrm{R}-\mathrm{sqr}=0.9844 \& \mathrm{RMSE}=12.88)\end{array}$ \\
\hline Voce Law & $\sigma=\mathrm{a}-\mathrm{b} \mathrm{e}^{-\mathrm{c} \varepsilon}$ & $\mathrm{a}, \mathrm{b}, \mathrm{c}$ & $\begin{array}{l}\mathrm{a}=1481, \mathrm{~b}=802, \mathrm{c}=2.149 \\
(\mathrm{R}-\mathrm{sqr}=0.9838 \& \mathrm{RMSE}=13.14)\end{array}$ \\
\hline Ghosh Law & $\sigma=\mathrm{a}\left(\varepsilon_{0}+\varepsilon\right)^{\mathrm{b}}-\mathrm{c}$ & & $\begin{array}{l}\mathrm{a}=1461, \mathrm{~b}=0.3748, \mathrm{c}=0.00041, \\
\sigma_{\mathrm{y}}=68.56 \\
(\mathrm{R}-\mathrm{sqr}=0.9884 \& \mathrm{RMSE}=12.19)\end{array}$ \\
\hline
\end{tabular}

\section{RESULTS AND DISCUSSION}

\subsection{Influence of Hardening Models on Loading Conditions and Bulge Height}

Fig. 3 shows the effect of different hardening models on internal pressure loading conditions and also bulge height. From fig. 3(a), it was observed that predicted bulge height by ghosh model suited well with the experimental bulge height. From the fig. 3 (b), it is observed that the internal pressure prediction by ghosh hardening model suited well with the experimental pressure loading. An error of 1 percent is observed for both ghosh and krupkosky hardening modeled with the experimental bulge height as is observed from fig. 3(a). Similarly from fig. 3 (b), it is observed that the loading paths of all the models different for different bulge heights when compared to the experimental data.

The final bursting pressure of ghosh model is in good agreement with the experimental bursting pressure. The ghosh hardening model prediction is high when compared to the all other hardening models as can be observed from the Table 3. The reason for ghosh model is in good agreement with the experimental data is due to the high accuracy in fitting the tensile test data with an R-sqr value

Figure 3. Hardening models effect on (a) bulge height and (b) bursting pressure

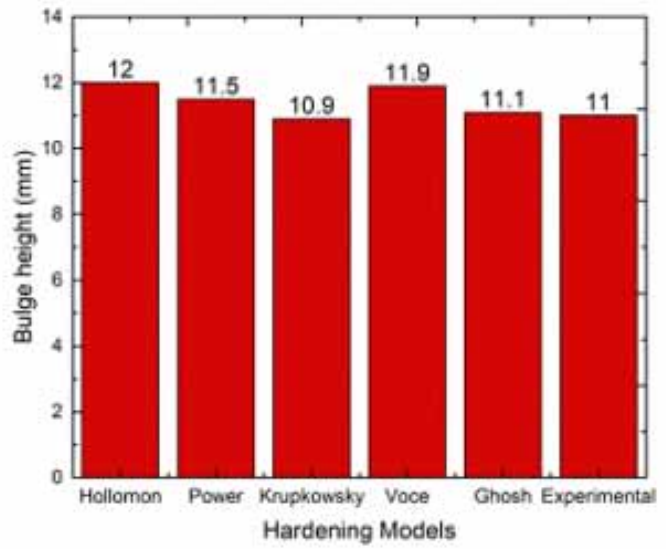

a

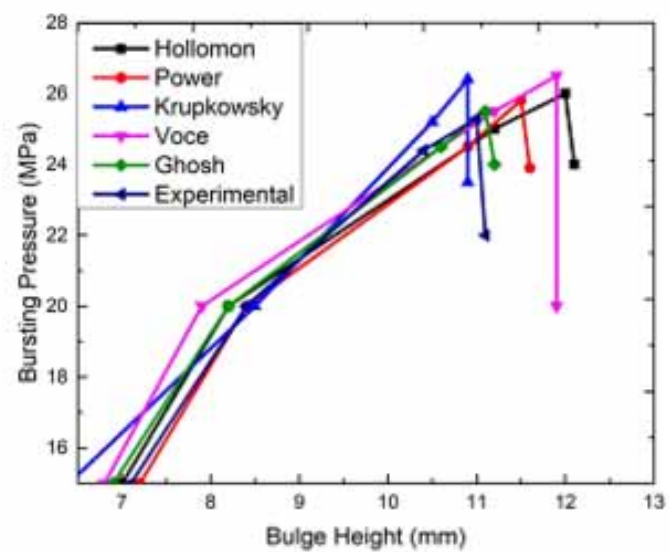

b 
of 0.9884 . When compared to all other hardening models krupkowsky la is also in good agreement with the experimental data since the prediction accuracy of the krupkowsky is also high with an R-sqr value of 0.9844 .

\subsection{Influence of Hardening Models on FLC}

Literature reveals that the anisotropic or distortional hardening behavior influences the FLC prediction for the sheet metals (Barlat et al., 2011; Mohanty et al., 2019). In the present study also, the FLC of the computed SS 304 influenced by the hardening models. Distortional hardening behavior was especially evident for the materials with high lankford coefficients like stainless steel (Lian et al., 2018). Fig. 4 represents the influence of hardening models in prediction of forming limit curves during the THF process. Both left hand right hand side of the FLC is predicted by considering different boundary conditions to obtain different strain paths. From the fig. 4, it is observed that ghosh hardening model is predicted well when compared to experimentally predicted FLC. The prediction capability of the hardening model depends mostly of the accuracy of fitting experimental stress strain curve. The accuracy of the ghosh model is high in terms of curve fitting so it has high FLC prediction accuracy. Higher the terms in the hardening model higher is the computation time (Banabic et al., 2013).

According to Fig. 4, the Hill 1990 with ghosh, voce and power hardening models afforded the sound inference of the FLC especially in the positive minor strain. Whereas, in the negative minor strain only ghosh hardening model predicted well with the experimental FLC hen compared to all other hardening models. It is already distinguished that localized necking provoke the plastic instability with an opposing to diffuse necking. This is the prime reason for the poor estimations in the negative minor strain in comparison with the experimental data. Material anisotropy significantly contributes the FLC predictions and the Hills 1990 yield criteria does not take full material anisotropy into consideration. Material anisotropy may or may not be the prime reason for the difference from the experimental FLC. The introduction of proper material anisotropy yield criterion may leads to complex formulations, so the yield function with particular material anisotropy can be further investigated. This is one of the prime reasons for the poor prediction in the left hand side of FLC.

\subsection{Failure Initiation During the THF Process}

In both numerical and experimental test instances, the tube failure initiation point is depicted in Fig. 5. The tube bursting beginning with the Ghosh hardening model is shown in Figure 5(a),

Figure 4. Hardening models effect on FLC

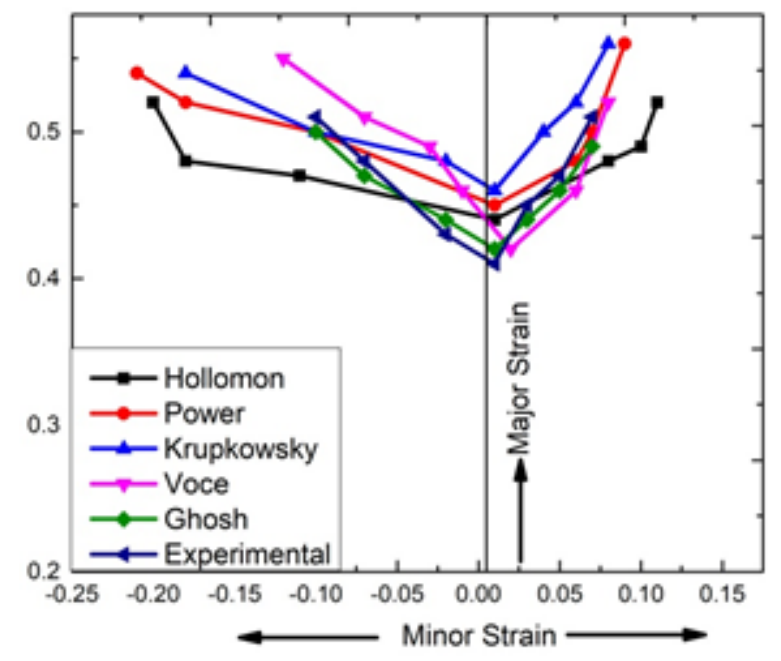




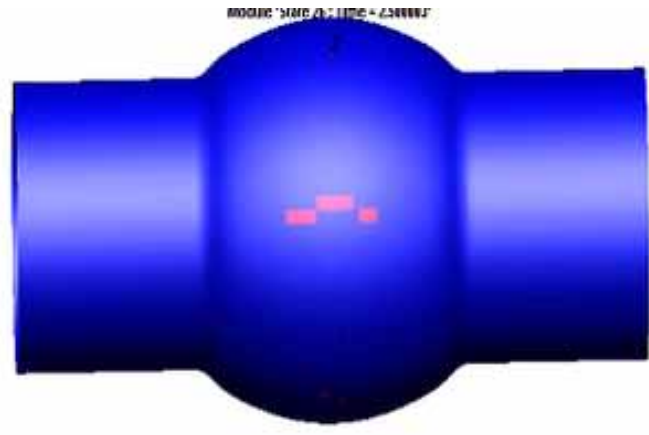

a

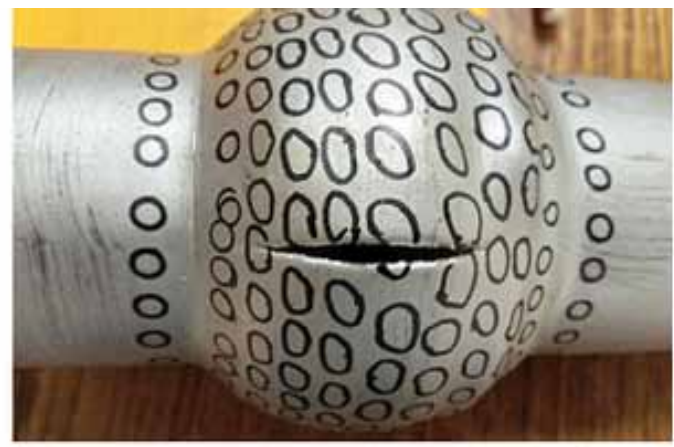

b

and the experimentally tested burst tube is shown in Figure 5(b). The failure prediction of the THF process is accurately predicted by the specified hardening model and yield criterion, as shown in fig. 5. When compared to the widely used Hills 1948 and Von-Mises yield criteria, Hills 1990 yield criteria takes stress in three rolling directions, allowing for more accurate prediction. Because of the anisotropic material features in the yield function, the failure prediction was enhanced in this study. This yield function employs regression analysis, a timedependent method for detecting the commencement of necking during tube specimen bulging (Merklein et al., 2010). The FLC of the tube material is predicted based on the current tube bulging specimen. The main advantage of this method for FLC prediction is that it investigates the complete strain range capabilities, resulting in a high prediction accuracy when compared to the experimental data test. Furthermore, FLC prediction using this tube bulging method has numerous advantages, as parasitic effects due to friction are avoided, and the necking region occurs at the pole of the bulged specimen, where bursting occurs (Banabic et al., 2013). The bursting of the tubular specimen occurred at the bulged pole location in this study as well and similar results are observed in the literature (Reddy et al., 2021).

\section{CONCLUSION}

Experiments and numerical simulations on open bulge tube hydroforming were carried out in this study, with different hardening models taken into account. The simulations were run using data from uni-axial tensile tests done in three different rolling directions. During the THF procedure, the predictions of loading conditions, bulge height, and FLC were investigated. The following findings were drawn based on the work that was completed:

1. There was a difference in the formability prediction of SS 304 with different hardening models.

2. Deformation data from uniaxial tensile tests were fitted with various hardening models, with R-sqr values of 0.9884 and 0.9844 for Ghosh and Krupkowsky laws, respectively.

3. The error between predicted burst pressure and bulge height by ghosh model and experimental results is less than $2 \%$.

4. The FLC prediction with ghosh hardening model is in good agreement with the experimental FLC curve.

5. The failure prediction between numerical and experimental is accurate with Hills 1990 yield criterion in connection with ghosh hardening model. 


\section{CONFLICT OF INTEREST}

The authors declare that there is no conflict of interest regarding the publication of this paper.

\section{ACKNOWLEDGMENT}

The authors would sincerely like to thank the department of metallurgical engineering and material science at IIT Bombay for providing research facilities and also the management of G Pulla Reddy Engineering College (Autonomous), Kurnool for providing the testing facilities and their constant support. 


\section{REFERENCES}

Alaswad, A., Benyounis, K. Y., \& Olabi, A. G. (2012). Tube hydroforming process: A reference guide. Materials \& Design, 33, 328-339. doi:10.1016/j.matdes.2011.07.052

Asnafi, N., \& Skogsgårdh, A. (2000). Theoretical and experimental analysis of stroke-controlled tube hydroforming. Materials Science and Engineering A, 279(1-2), 95-110. doi:10.1016/S0921-5093(99)00646-2

Banabic, D., Lazarescu, L., Paraianu, L., Ciobanu, I., Nicodim, I., \& Comsa, D. S. (2013). Development of a new procedure for the experimental determination of the forming limit curves. CIRP Annals, 62(1), 255-258. doi:10.1016/j.cirp.2013.03.051

Barlat, F., Gracio, J. J., Lee, M. G., Rauch, E. F., \& Vincze, G. (2011). An alternative to kinematic hardening in classical plasticity. International Journal of Plasticity, 27(9), 1309-1327. doi:10.1016/j.ijplas.2011.03.003

Ge, Y. L., Li, X. X., Lang, L. H., \& Ruan, S. (2017). An adaptive loading path design method for tube hydroforming using fuzzy logic theory. Journal of the Brazilian Society of Mechanical Sciences and Engineering, 39(7), 2607-2617. doi:10.1007/s40430-016-0626-3

Ghazani, M. S., \& Eghbali, B. (2018). A ductile damage criterion for aisi 321 austenitic stainless steel at different temperatures and strain rates. Arabian Journal for Science and Engineering, 43(9), 4855-4861. doi:10.1007/ s13369-018-3191-5

Gronostajski, Z. (2000). The constitutive equations for FEM analysis. Journal of Materials Processing Technology, 106(1-3), 40-44. doi:10.1016/S0924-0136(00)00635-X

Hashemi, R., Assempour, A., \& Abad, E. M. K. (2009). Implementation of the forming limit stress diagram to obtain suitable load path in tube hydroforming considering M-K model. Materials \& Design, 30(9), 3545-3553. doi:10.1016/j.matdes.2009.03.002

Hashemi, R., Mamusi, H., \& Masoumi, A. (2014). A simulation-based approach to the determination of forming limit diagrams. Proceedings of the Institution of Mechanical Engineers. Part B, Journal of Engineering Manufacture, 228(12), 1582-1591. doi:10.1177/0954405414522448

Keeler, S. P. (1961). Plastic instability and fracture in sheets stretched over rigid punches (Doctoral dissertation). Massachusetts Institute of Technology.

Lian, J., Shen, F., Jia, X., Ahn, D. C., Chae, D. C., Münstermann, S., \& Bleck, W. (2018). An evolving nonassociated Hill48 plasticity model accounting for anisotropic hardening and r-value evolution and its application to forming limit prediction. International Journal of Solids and Structures, 151, 20-44. doi:10.1016/j. ijsolstr.2017.04.007

Merklein, M., Kuppert, A., \& Geiger, M. (2010). Time dependent determination of forming limit diagrams. CIRP Annals, 59(1), 295-298. doi:10.1016/j.cirp.2010.03.001

Mohanty, S., Regalla, S. P., \& Rao, Y. D. (2019). Robot-assisted incremental sheet metal forming under the different forming condition. Journal of the Brazilian Society of Mechanical Sciences and Engineering, 41(2), 74. doi:10.1007/s40430-019-1581-6

Naghibi, M. F., Gerdooei, M., \& Jooybari, M. B. (2016). Experimental and numerical study on forming limit diagrams of 304 stainless steel tubes in the hydroforming process. Journal of Materials Engineering and Performance, 25(12), 5460-5467. doi:10.1007/s11665-016-2382-z

Omar, A., Tewari, A., \& Narasimhan, K. (2015). Formability and microstructure evolution during hydroforming of drawing quality welded steel tube. Journal of Strain Analysis for Engineering Design, 50(7), 542-556. doi: $10.1177 / 0309324715600983$

Pambhar, A., \& Narasimhan, K. (2013). Prediction of stress and strain based forming limit diagram during tube hydroforming process. Transactions of the Indian Institute of Metals, 66(5-6), 665-669. doi:10.1007/s12666013-0336-9

Papasidero, J., Doquet, V., \& Mohr, D. (2015). Ductile fracture of aluminum 2024-T351 under proportional and non-proportional multi-axial loading: Bao-Wierzbicki results revisited. International Journal of Solids and Structures, 69, 459-474. doi:10.1016/j.ijsolstr.2015.05.006 
Reddy, B. V., Kondayya, D., Goud, E. V., \& Reddy, P. V. (2021). Yield criterion influence on the formability prediction of SS 304 by tensile tests and bulge tests during tube hydroforming process. Multiscale and Multidisciplinary Modeling, Experiments and Design, 1-10.

Reddy, P. V., Reddy, B. V., \& Ramulu, P. J. (2019). An investigation on tube hydroforming process considering the effect of frictional coefficient and corner radius. Advances in Materials and Processing Technologies, 1-20. $.10 .1080 / 2374068 X .2019 .1707437$

Reddy, P. V., Reddy, B. V., \& Ramulu, P. J. (2020). Effect of heat treatment temperatures on formability of SS 304 during tube hydroforming process. SN Applied Sciences, 2(2), 205. doi:10.1007/s42452-020-2026-7

Reddy, P. V., Reddy, B. V., \& Rao, P. S. (2018). A numerical study on tube hydroforming process to optimize the process parameters by Taguchi method. Materials Today: Proceedings, 5(11), 25376-25381. doi:10.1016/j. matpr.2018.10.341

Safikhani, A. R., Hashemi, R., \& Assempour, A. (2009). Some numerical aspects of necking solution in prediction of sheet metal forming limits by strain gradient plasticity. Materials \& Design, 30(3), 727-740. doi:10.1016/j. matdes.2008.05.028

Thanakijkasem, P., Pattarangkun, A., Mahabunphachai, S., Uthaisangsuk, V., \& Chutima, S. (2015). Comparative study of finite element analysis in tube hydroforming of stainless steel 304. International Journal of Automotive Technology, 16(4), 611-617. doi:10.1007/s12239-015-0062-x

Voce, E. (1948). The relationship between stress and strain for homogeneous deformation. Journal of the Institute of Metals, 74, 537-562.

Wang, N. H., Yang, L. F., \& Wu, C. L. (2015). Comparison of constitutive relationships of tubular materials based on incremental theory and total strain theory. Materials Research Innovations, 19(sup8), S8-710.

Wang, Y., Lang, L., Zafar, R., Sun, Z., \& Zhang, Q. (2016). Investigation into the overlapping sheet hydraulic bulge and its formability. Journal of the Brazilian Society of Mechanical Sciences and Engineering, 38(6), 1635-1645. doi:10.1007/s40430-015-0430-5

Wang, Y., \& Peng, W. (2016). A deformation analysis and experimental study for a novel full kinematic incremental forming. Australian Journal of Mechanical Engineering, 14(2), 73-81. doi:10.1080/14484846.2015.1093210

Yuenyong, J., Suthon, M., Kingklang, S., Thanakijkasem, P., Mahabunphachai, S., \& Uthaisangsuk, V. (2018). Formability prediction for tube hydroforming of stainless steel 304 using damage mechanics model. Journal of Manufacturing Science and Engineering, 140(1), 011006. doi:10.1115/1.4038208

Zhang, C., Leotoing, L., Zhao, G., Guines, D., \& Ragneau, E. (2011). A comparative study of different necking criteria for numerical and experimental prediction of FLCs. Journal of Materials Engineering and Performance, 20(6), 1036-1042. doi:10.1007/s11665-010-9729-7

Zhang, R., Shao, Z., \& Lin, J. (2018). A review on modelling techniques for formability prediction of sheet metal forming. International Journal of Lightweight Materials and Manufacture, 1(3), 115-125. doi:10.1016/j. ijlmm.2018.06.003

Zribi, T., Khalfallah, A., \& BelHadjSalah, H. (2013). Experimental characterization and inverse constitutive parameters identification of tubular materials for tube hydroforming process. Materials \& Design, 49, 866-877. doi:10.1016/j.matdes.2013.02.077

Perumalla Janaki Ramulu is an Associate professor in the Department of Mechanical Design and Manufacturing Engineering, School of Mechanical, Chemical and Materials Engineering at Adama Science and Technology University, Adama, Ethiopia. He was educated in the Vijay Rural Engineering College, Nizamabad, Telangana, National Institute of Foundry and Forge Technology, Ranchi, Jharkand and Indian Institute of Technology, Guwahati, Assam. Obtained his B.Tech in 2001, M.Tech in 2004 and PhD in 2013 all are from Indian Institutions. He published as an author/ co-author more than 100 papers including journals and conferences. He was the supervisor many UG, PG and PhD students. He is also acting as Director for centre of excellence for Advanced Manufacture Engineering since 2017. 